\title{
Wiki Use That Increases Communication and Collaboration Motivation
}

\author{
Robyn Davidson \\ Business School \\ The University of Adelaide \\ robyn.davidson@adelaide.edu.au
}

\begin{abstract}
Communication and collaboration can be readily enabled by the use of many ICT tools. A wiki, which is an easily accessible and editable website, is one such platform that provides the opportunity for students to work on group projects without the barriers that arise from traditional group work. Whilst wiki use is becoming more common, its use in education is patchy and pedagogical reasoning and evaluation of such use is under explored. This paper addresses the gap in pedagogy and evaluation in the context of accounting studies. A traditional assessment task of writing an essay that involved a research and knowledge component was redesigned to enable groups to communicate and collaborate at a distance using a wiki. Through participant observation and student reflections of the group project, a wiki was found to be an effective platform to communicate and collaborate on a group project and enabled different barriers to be broken down. Wikis provide ubiquitous access to group work, organisation and version control, levels the playing field for dominant and shy students, and provides transparency for non-performers and high achievers.
\end{abstract}

\section{Keywords}

Wiki, communication, collaboration, motivation, ICT tools, group work

\section{Introduction}

The importance of communication and collaborative skills are evident in many professions. This is particularly so in the accounting profession which has stressed the need for graduates to have more than just good technical knowledge. In choosing graduates for employment the applicants' ability to communicate and collaborate in a team environment is considered essential. The traditional answer to improving students' communication and collaborative skills is to give them a group work assignment; however, traditional group work itself is not without problems. For instance, group work seldom results in all group members being equally driven and therefore problems arise when all members do not turn up for meetings or do not make an equal contribution. This paper describes how a group work assignment is facilitated with the use of a wiki platform that creates a learning environment that solves some of the problems encountered with group work.

A wiki is a website that is easily edited. Pages can be created, linked to, and edited by any number of users (Cunningham, 2012). Ward Cunningham created the first ever wiki called WikiWikiWeb in 1995 so programmers could write web pages to share information about people, projects and patterns that have changed the way they program (Cunningham, 2011). The world's biggest and best-known wiki is Wikipedia. Started in 2001 and open to the entire population to edit, it now has over 3.9 million pages (Wikipedia, 2012). Wikis are freely available for academic use on many commercial websites such as Wikispaces (http://www.wikispaces.com.au) as well as being incorporated into most Student Management Systems such as Blackboard. 
A wiki is one of a few Web 2.0 applications that have opened the door to new and innovative teaching methods (Augar, Raitman, \& Zhou, 2004; Ehlers, 2009; Ferris \& Wilder, 2006; Hazari, North, \& Moreland, 2009). Facebook has been used in the teaching of architecture (McCarthy, 2009); Wimba has been used to provide feedback in a multicultural teaching environment (Warner, 2009); and wikis have been used in teaching physical education (Mears, 2009), nursing (Ciesielka, 2008), languages (Matthew, Felvegi, \& Callaway, 2009), law (Ruyters, Douglas \& Law, 2011) and information systems (Lending, 2010). Wikis are being used in education to varying degrees of success however; the amount of literature and success stories is limited.

Participant observation and student reflection of the group project provides evidence that a wiki is an effective platform to communicate and collaborate and enables barriers to be broken down. Wikis provide ubiquitous access to group work, organisation and version control, levels the playing field for dominant and shy students, and provides transparency for non-performers and high achievers.

Academics may find the experiences documented here useful when creating tasks designed to capture learning outcomes centred on knowledge and understanding of course content in addition to practicing and demonstrating communication and collaboration skills. While this paper has a focus on accounting studies the ideas are transferrable across disciplines.

The possibilities for wiki use are far wider reaching than the ability to facilitate communication and collaboration among student groups. There is no reason why this technology cannot be used to enable collaboration on research projects or to facilitate the sharing and development of resources among academics across institutions and disciplines. Many institutions make their course material available on-line. The Massachusetts Institute of Technology (MIT) led the way in 2002 in an attempt to sustain its reputation for innovation and leadership. Starting with fifty courses online, it now has over two thousand of which many have been translated into other languages (MIT OpenCourseWare, 2012; Wiley \& Gurrell, 2009). There is no reason why individuals cannot take this one step further and collaboratively build up a depository of knowledge and teaching resources in a specific discipline (Bonk, 2009). For example, WikiEducator (wikieducator.org), which is built on the same platform as Wikipedia, is open to all to contribute and has a focus on teaching pedagogy, education research and course related materials. WikiEducator is an evolving community with the intention of developing free content for eLearning and building open education resources (WikiEducator, 2012). Many other wikis in use are restricted to a select group of users to share ideas and collaborate on projects. This concept is explored in the further possibilities section of this paper.

In the following sections of this paper, the rationale behind using wikis and the assessment task is described followed by evidence of the effectiveness of their use. In the concluding sections, suggestions for implementation are provided and possibilities for broadening the use of wikis in academia are raised.

\section{Background}

There has long been concern over the lack of communication and other generic skills in accounting graduates. The 1990 Matthews Report on Accounting in Higher Education (Matthews, Jackson, \& Brown, 1990) recommended integrating communication, collaboration and other skills into the accounting discipline. Two decades later, a large study by the Australian Learning and Teaching Council (ALTC) (Hancock, Howieson, Kavanagh, Kent, Tempone \& Segal, 2009) produced similar findings in that communication and collaboration skills are still identified as essential skills that are lacking in accounting graduates.

University graduate attributes encompass the essential qualities, knowledge, and capabilities that students should develop during the course of their studies. The majority of Australian universities 
have a list of graduate attributes that describe the skills they expect a student to have upon graduating. These usually include a high order of interpersonal understanding, teamwork and communication skills among others.

In fields of study such as accounting, similar expectations are placed on the students from the professional accreditation and accounting bodies (AACSB, 2012; ICAA \& CPA, 2009) and major employers of our graduates (Bui \& Porter, 2010; Hancock, et al., 2009, 2010). We are constantly being reminded of the importance of producing graduates who can think creatively and innovatively, and have the skills to communicate and collaborate.

For example, Bui and Porter (2010) found that employers consider graduates' face-to-face communication skills to be generally adequate but their writing skills are poor and they are ill prepared for communicating in the work environment. Whereas, Hancock et al. (2010) found that communication in all forms, coupled with teamwork, problem solving and self-management and interpersonal skills are highly sought after in graduates and will make a difference in advancement within the workplace. Not only does the profession recognise the lack of skills: surveys of accounting graduates found a perceived deficiency in interpersonal skills, oral expression (De Lange, Jackling \& Gut, 2006), and communication and group interaction skills (Carr, Chua \& Perera, 2006).

There is no shortage of evidence which points towards graduates of today not meeting the expectations of their university or potential employers. Graduates of today are no different to twenty years ago when the Mathews Report (Matthews, et al., 1990) was produced even though the student cohort has changed. Today we have technologically aware students with more ICT resources than ever before at their fingertips and yet the problems of twenty years ago remain. The question is still, "how can we produce graduates with better communication and collaboration skills?"

\section{Teaching rationale}

Group work has long been held as a possible means to increase students' communication and collaboration skills and yet it is not without its problems (McInnis \& Devlin, 2002). Many of the traditional problems of group work can be overcome with the use of a wiki.

Not all students have a positive attitude to group projects (Chapman, Meuter, Toy \& Wright, 2010; Pfaff \& Huddleston, 2003; Underwood, 2003). The author has first-hand experience with problems experienced in administering traditional group work. At times it seems as though the barriers of dealing with these problems outweigh the benefits to the students. A wiki has the potential to reduce these barriers while providing enhanced benefits. Typically, the most frequent complaints are:

- Some of my group members never turn up to meetings.

- We have lost our work, we got our files mixed up or someone's computer crashed

- A group member is being bossy and/or I'm too shy to say anything

- It is not fair that my grade will get pulled down by the slack students. I have to do their work as well so that does not happen.

These problems can be largely overcome through the use of a wiki.

With students' busy schedules and conflicting timetables, it is extremely difficult for students to arrange a time that all group members can meet face-to-face. Not only is the timing a constraint but some live a reasonable distance from the university campus and it is impracticable to travel for a single meeting at a time that suits all group members. Wikis give ubiquitous access to work from anywhere with an Internet connection. 
Email has traditionally been a way for groups to share information. Group members can send files, such as journal articles to each other, as well as the document they are working on. It is easy to lose track, however, of files and update old versions. A wiki provides a common place where files can be uploaded, links created to resources, and the group can share ideas and work on the drafts and the final document. A wiki provides a way to organise group work and version control. At any point in time, previous versions can be viewed and reverted to, if necessary.

Groups typically have at least one dominant and one shy student. In a face-to-face situation, the shy student will feel intimidated and not be able to put forward their ideas; ideas that could be very worthwhile. The dominant student will lead the discussion and make decisions for the group. A wiki levels the playing field in that students can post their ideas on the wiki for others to read. While this does not prevent the dominant student from making the final decisions and overwriting others, it does at least give all group members a chance to be heard.

There is often a conflict of interest between high-achieving students and those who are unconcerned about their grade. The high achievers are concerned that their individual contributions will not be fairly evaluated (Gammie \& Matson, 2007). The high-achievers will do extra work to make up for the non-performers so that their grade is not dragged down while the non-performers will let them. McInnis and Devlin (2002) cited this as one of the most common reasons why students are reluctant to participate in group assessments. The wiki provides a transparent environment where the contribution by all group members can be easily monitored. The instructor can easily see who has contributed what and adjust grades accordingly. There is no need for all group members to get the same grade or for group members to have to decide on a percentage contribution for each member. A wiki creates a much fairer environment to base the assessment of group work.

\section{Implementation}

The author is responsible for a postgraduate intermediate level financial accounting course at the University of Adelaide, Australia. This is a conversion Master's degree in professional accounting. Entry is open to students who have completed another degree and require accounting qualifications. The majority of students are international and English is their second language. They typically do not like to participate in class discussion; hence, the issue of communication and collaboration skills is even more important. In the semester this assessment took place, there were 117 students enrolled.

The course content has an emphasis on how to interpret and apply accounting standards. It is impossible to cover every standard so several are chosen that either demonstrate key concepts or will be most relevant for the student in their working life (e.g. accounting for leases, intangible assets, and financial instruments). The emphasis is on interpretation and application rather than rote memorisation. The nature of the material renders the course very technical and it is often perceived as very dry and uninteresting.

In the past, a major essay was a component of the assessment items. This was an individual assignment that included an element of research, analysis and "writing up" of a given topic focused on one component of the course. Students would often lack motivation to do well as they found the task uninteresting and difficult and so only wanted to pass, or at least get some marks, towards the final grade. From the instructor's perspective, reading similar essays that students have obviously put minimal time and effort into is frustrating and a concern that students are not engaging with their studies but merely doing the minimum required. This was the driving force behind changing the assessment task so that students could collaborate and communicate, hence learn from discussing issues with each other, and hopefully they would be motivated if an environment conducive to collaborative work was provided. Therefore an assessment task was 
designed that involved groups of five students gathering information and writing a report on a wiki made available on the university Blackboard Student Management System.

\section{The task}

Students were to imagine that they were new graduates working in a private sector firm. A conversation with their manager demonstrated a lack of knowledge of the Australian accounting standard setting environment. The manager later asked the graduate for further clarification. The graduate, along with the other new graduates (the student's group members) decide to gather and provide the manager with the information required by using a wiki. This would allow them to demonstrate the power of a wiki for knowledge sharing within the organisation and, most importantly, demonstrate their ability to be creative and innovative, and to show off their organisational and collaboration skills. Students were given no boundaries on how the information was to be presented and were told to "be as creative and innovative as they like" . A brief history of the Australian accounting standard setting environment was given in a lecture. This task was designed for students to research the topic further and discover for themselves how Australian accounting standards are adopted from international standards. This in turn led them to research international standards and exposure drafts.

In terms of graduate attributes, this task required research skills to find the required information which had to be analysed and summarised, it was designed to increase the students' level of knowledge of the discipline, and give them the opportunity to solve a problem using creative and innovative techniques while working in a cooperative manner with their peers. In order to gauge student perceptions of the effectiveness of the task and reinforce to the students what they have achieved, each was required to complete a reflective piece about group work and the wiki experience.

\section{Implementing the task}

Groups were assigned randomly and students did not know their group members. Initially, some students were alarmed at being put into a group with students they did not know. It was explained to them that in the business world they may be asked to do a task with other employees from the same office or a different office that they have not met before. Furthermore, they did not have to meet in person but could introduce themselves to each other via an "introduction" page on the group wiki.

There was initial reluctance to use the wiki with some students expressing that they did not know what it was or how to use it. Generation-Y students are supposed to be technologically confident and have an anytime, anywhere work attitude (Sheahan, 2005) which the wiki workspace provides. The students were provided with a "wiki testing site," a space where they could anonymously create and edit pages, practice formatting, insert images and create links.

One of the advantages of using a wiki is that the lecturer can see what progress is being made. The students generally got off to a slow start, which could have been caused by a number of factors such as pressure to do other assignments first and a general sluggishness to get started in addition to their reluctance to use a new technology. However, when they did get started, it was an easy task for the instructor to view each wiki and leave encouraging comments.

When the wikis were completed students were also required to complete a reflective piece. This reflective piece required students to comment on the assignment and include their views about working in groups, working on the wiki, the learning process, and reflect on what they learnt and

\footnotetext{
${ }^{1}$ Assignment handout/task sheet is available by contacting the author, robyn.davidson@adelaide.edu.au
} 
what they could have done better. This data along with instructor observations form the basis of determining the effectiveness of the assignment.

\section{Findings}

The reflective comments made by students give an insight into their views about the assignment. Some students were hesitant to start for fear of doing something incorrectly as they had not done an assignment on a wiki before, however they did appear to be excited by the prospect. Feedback included:

I didn't think it was a good idea at the beginning, because I had never heard about Wiki before, it was completely new to me. I was afraid I may not be able to handle it.

I am a little confused how to submit report by wiki. Later I found it is quite easy. I thought it is more convenient to use wiki to communicate with group members.

When I learnt our assignment is related to wiki form, I felt very excited and looked forward to doing it.

Reflective comments and observations by the instructor were generally positive indicating that students would prefer to undertake group work using a wiki as it assists in meeting, sharing work and provided a more transparent working environment.

\section{Ubiquitous access}

Generally students considered the wiki as a good way to collaborate and complete group work as it overcomes the obstacle of having to find a time to physically meet which is often difficult with their conflicting timetables. They can add information, comment, and edit each other's work at any time and can gradually build on their collective knowledge to create the final product. On reading through the discussion and draft pages it was pleasing to see students finding relevant information, discussing it among themselves, and summarising and applying it in the context of the task. Students commented:

Wiki was a good idea as we all are enrolled into different courses at the same time, that makes it difficult to coordinate and fix up a meeting time with all the group members.

The most brilliant thing was we did not need to meet our group members which would save time.

I really thought it was a good idea as it could make group communication easier, less time consuming. ... I thought it was a great way to share information and knowledge as well.

\section{Organisation and version control}

The wikis were monitored periodically to assess the progress students were making in addition to being marked on completion. Groups generally created several pages to post resources and discuss issues. They placed links to relevant web sites, inserted images and uploaded files and worked on their final report in a cooperative manner. Clearly the organisation and version control enabled by using a wiki was beneficial to group effectiveness as evidenced by several student comments including:

Wiki is a very useful and simple tool to work on or discuss about a particular issue in a group where coordination between group members is most important. It reduces duplication of tasks. As compared to the traditional way of working where group member 
needed to meet or send emails, Wiki makes it easier for the group to work together effectively and efficiently.

Because wiki would provide us a platform to communicate and express our own ideas about our work we could make contributions and changes to each other's work as well. At any time we could review changes and see older versions in addition to seeing who made what changes.

\section{Dominant and shy students}

Some students commented that it was strange to not actually know who they were working with while others thought the wiki provided a relatively anonymous and easy way to communicate. The wiki enabled shy students to have a voice that they may otherwise not have.

I felt I had a lot more input than I would normally be able to doing group work. I liked the anonymously of it.

I am usually too shy to speak up in group meetings, but the wiki allowed me to put my thoughts forward.

I am an improved team worker definitely. Specifically, during this exercise, I learned how to express my opinions, how to persuade others and how to listen to others.

\section{High achievers and non-performers}

Traditionally with group work, students are asked to provide a statement that ascertains the percentage of contribution from each member. As with all group work, non-performers will be a problem. The history function of the wiki highlights these non-contributing students. The wiki has a feature that enables retrieval of the number and percentage of total pages saved and total lines modified by each student. In addition, it has the capability to drill down and see exactly what each member contributed. On marking the assignments, the students' grades can be adjusted in line with the quality and quantity of their contribution thus making assessment fairer and protecting the performing students from being dragged down by non-performers. However, care was taken not to judge students on the percentage of contribution only as a small contribution could be a very well researched and written piece that provides far more valuable input than a larger contribution which could be a cut and paste of background information for other group members to read. Hence instructors needed to use professional judgement to determine the value of a contribution. A well designed task and marking rubric can help instructors judge a student's work and reward those students that do make valuable contributions. Students appreciated this transparency as evidenced by these comments:

I like that the teacher can see what we are doing. It makes us start and do something.

I felt that I was being judged on my contribution, or at least I could prove what I did if needed.

However, even with the transparency of the wiki some students preferred individual work because they were concerned their mark could be lowered.

In general, I am against the group assignment because may be I do well but my partner does not do the required task then we will be assessed together and we will get the same mark. I like to work individually because this manner of working will give me the mark I deserve 


\section{Suggestions for implementation}

The evidence would suggest that using a wiki to facilitate group work has many advantages and overcomes problems of traditional group work. However, for implementation to be successful, a number of factors need consideration.

The task should be conducive to group work and ensure that the learning outcomes are achieved by the task. For instance, a task that requires gathering and sharing of information and discussion to further understand the course material is ideal. Instructors should try to avoid tasks where students can divide it into smaller segments to individually complete and then bring the pieces together at the end. Such tasks can result in a disjointed final product that students do not understand in its entirety.

It is imperative to ensure that students have a clear understanding of what is required. This ties in with the previous point of ensuring learning outcomes can be achieved by the task. If students have a clear indication of the required learning outcomes and what is expected of them they can focus on the required task. Some students were at first confused and unsure of what was expected, as evidenced by the comment below. Clearly expressing the task is paramount to success.

Because we are given no fixed style of the way undertaking this assignment, so at the very beginning we have no ideas on how to begin.

It is also important to ensure that supporting resources are available that provide an overview of how to use a wiki. This could be written instructions or short videos on how to create and edit wiki pages. It may also be links to YouTube videos that give overviews of what wikis are and how they can be used. Students should be encouraged to experiment and discover the new technology for themselves; just as they would if faced with a software application they hadn't used before in the workplace. To get students started and to help them overcome their initial fear of using a new technology, students can complete a simple task such as introducing themselves to their team members on an introductions page on the wiki.

There were some technical issues with the wiki editing tools. Some students expressed their frustration at formatting their text in the editing function, only to have it look different when it was saved. Furthermore, a page can only be edited by one student at a time, therefore if two students open a page in the edit function and work on it at the same time the last to save will overwrite the previous changes. If issues like this are explained in advance students will understand how the wiki works and take care to always save a copy of their work to assist re-posting it. The group should also be encouraged to make rules about how they make decisions on editing the wiki. For instance, rather than altering or replacing another students work without a reason comments could be left as to what changes have been made and why one version is better than another.

... the problem is that anyone can make change to anything even if the changes are incorrect. And it is kind of annoying when your contribution always been deleted or replaced without a proper reason. It was quite disappointing when you actually want to contribute something which is really useful.

These technical issues are problems with the Blackboard wiki application and other wiki applications may function better. However, within Blackboard, the instructor has the ability to easily import student groups and allocate those groups to wikis. This is very convenient for the instructor when dealing with large classes. However, this may not be the case with using an external wiki. There are costs and benefits and the slightly better functionality found on a wiki such as Wikispaces may be offset by the extra workload of administering a large number of groups.

Engaging students in reflection and feedback is an important part of the learning process. This can be incorporated into the assessment task by asking students to write a short piece on how the group 
worked together, how they each added to the build-up of knowledge and contributed to the final product, and importantly what they gained from the experience. Instructors can also be involved in the learning process. As the instructors have access to the wiki, they can check in often and see how the students are progressing and leave encouraging comments and suggestions for improvement. This allows instructors to contribute to the learning process rather than merely judging the students ability.

\section{Further possibilities}

Future implementations of this assessment could be evaluated using a more rigorous means. Empirical data could be captured in the form of a survey and evaluated using statistical analysis such as that used by Hazari et al. (2009).

The assessment task could be expanded so that it covers more of the course content over a longer time period. This would enable students to build a better rapport with each other and to practice the iterative nature of working on a collaborative project to a greater extent. As the instructor has access to the wikis, periodic checks can be made of group progress. Marks could be assigned for early contributions as this may encourage students to make an early start, thus promoting time management skills. Continuous feedback could also be left directly on the wiki site which would encourage students and promote a positive learning environment.

The ideas presented here could also be adopted in another discipline. As mentioned earlier in this paper communication and collaboration skills are not unique to the accounting profession and whilst wikis have been used in other areas of education their use is not widespread. The ideas presented here could provide the scaffolding on which to design a wiki based assessment.

The use of a wiki is not restricted to motivating students to communicate and collaborate. There is merit in its use in academia to facilitate communication and collaboration among colleagues across institutions. ICT tools such as Skype are already used to facilitate video conference calls to colleagues and email is used to share resources and documents. When working on group collaborative projects a wiki could be used to help in the organisation and sharing of resources and version control of documents. Websites such as Wikispaces provide a secure and free wiki for educational use. This can easily be set up and group members invited. Participants can then create pages and add information, files and links.

Wikis could be used as a depository of resources for academics in a specialized field. For instance, academics in financial accounting could post lecture notes, worked examples, exam questions, videos, assignment questions and solutions to the wide range of subject areas covered in our courses. Obviously these would not want to be made available to the student population but restricted to academics working in this field. This sharing of resources would have numerous benefits. Sharing teaching approaches and innovations cross-institutionally has the potential to increase teaching standards and teaching excellence. Reuse saves time in developing new courses and course content. If colleagues are spared from having to produce new material it frees up time and may provide inspiration for the development of further material that all users can benefit from. Collectively working on course content material will result in less errors and improved content for all. In an area that has frequent changes, such as accounting standards, the latest requirements can be posted, interpreted and discussed ensuring that course material and academics are up-to-date. On a personal level, sharing within a disciple community can promote personal growth and respect among colleagues (Bonk, 2009).

\section{Conclusion}

The problem of graduates not having the attributes the university and the accounting profession would like them to have when they graduate has been on the academic and professional agenda for decades. How to solve this problem is not going to happen in one class in one semester, however, if academics think beyond the traditional delivery methods incremental changes can occur. 
In this instance a group assignment was set that required the students to think outside traditional group work methods. The students introduced themselves, discussed the task, shared the results of their research and wrote up their finding using a new collaborative technology tool; a wiki. Students were at first hesitant to start and found the task daunting as using a wiki and working with people they did not know was outside their comfort zone. However, overall the majority of students indicated they were pleased with the assignment task once they got started. On reflection students felt they had gained valuable communication and collaboration skills. The wiki provided them with ubiquitous access to the group work and enabled them to update their findings and easily see which team members had made changes enabling greater version control over their work. All students had an equal chance to participate benefitting shy students in particular, as they generally do not speak up in a traditional face-to-face group meeting. The transparency enables the instructor to see exactly who has contributed and provides a fairer assessment for both nonperformers and high achievers.

The author intends to continue making improvements to the group assignment and using wikis. What are otherwise "dry" and "uninteresting" classes can be made exciting and interesting with a little creative thought and planning. For a first trial of this new and innovative method of completing assignments, and given the added complexity that arises when the class cohort consists of mainly international students, on the whole it is felt that students demonstrated an improved level of communication and collaboration skills and gained an increased level of understanding of the course content than they did with an individual assignment. Judging from student comments, the majority did feel as though they improved in these areas, hence the objectives of the assignment were met.

While wiki use can create a classroom without walls, the possibilities should not be restricted to the classroom. From a cross-institutional perspective, the possibilities are infinite. Academics can use wikis and other ICT tools to share knowledge to enhance scholarship and teaching. The farreaching arms of the Internet do not restrict us to collaborating only with our neighbouring universities; we have easy access to all corners of the globe and the most inspiring minds.

\section{References}

AACSB. (2012). Eligibility procedures and accreditation standards for accounting accreditation. AACSB International - The Association to Advance Collegiate Schools of Business. Tampa, Florida.

Augar, N., Raitman, R., \& Zhou, W. (2004). Teaching and learning online with wikis. In Proceedings of Australasian Society for Computers in Learning in Tertiary Education Conference (ASCLITE), Perth, 5-8 December. Retrieved from http://www.ascilite.org.au/conferences/perth04/procs/augar.html

Bonk, C. J. (2009). The world is open: How web technology is revolutionizing education. San Francisco, CA: Jossey-Bass.

Bui, B., \& Porter, B. (2010). The expectation-performance gap in accounting education: An exploratory study. Accounting Education: An International Journal, 19(1), 23-50.

Carr, S., Chua, F., \& Perera, H. (2006). University accounting curricula: The perceptions of an alumni group. Accounting Education: An International Journal, 15(4), 259-376.

Chapman, K. J., Meuter, M. L., Toy, D. , \& Wright, L. K. (2010). Are student groups dysfunctional? Perspectives from both sides of the classroom, Journal of Marketing Education. 32(1), 39-49.

Ciesielka, D. (2008). Using a wiki to meet graduate nursing education competencies in collaboration and community health. Educational Innovations, 47(10), 473-476.

Cunningham, W. (2011). Invitation to the patterns list. Retrieved from http://c2.com/cgi/wiki?InvitationToThePatternsList 
Cunningham, W. (2012). Wiki wiki web. Retrieved from http://c2.com/cgi/wiki?WikiWikiWeb.

De Lange, P., Jackling, B., \& Gut, A. M. (2006). Accounting graduates' perceptions of skills emphasis in undergraduate courses: An investigation from two Victorian universities. Accounting \& Finance, 46(3), 365-386.

Ehlers, U. D. (2009). Web 2.0 - e-learning 2.0 - quality 2.0? Quality for new learning cultures. Quality Assurance in Education, 17(3), 296-314.

Ferris, S. P., \& Wilder, H. (2006). Uses and potentials of wikis in the classroom. Innovate: Journal of Online Education, 2(5). Retrieved from http://www.innovateonline.info/index.php?view=article $\&$ id $=258$

Gammie, E., \& Matson, M. (2007). Group assessment at final degree level: An evaluation. Accounting Education: An International Journal. 16(2), 185-206.

Hancock, P., Howieson, B., Kavanagh, M., Kent, J., Tempone, I., \& Segal, N. (2009). Accounting for the future: More than numbers. A collaborative investigation into the changing skill set for professional accounting graduates over the next ten years and strategies for embedding such skills into professional accounting programs. Sydney, Australia: Australian Learning and Teaching Council (ALTC).

Hancock, P., Howieson, B., Kavanagh, M., Kent, J., Tempone, I., \& Segal, N. (2010). Accounting for the future. In E. Evans, R. Burritt \& J. Guthrie (Eds.), Accounting Education at a Crossroads in 2010. (pp. 54-62) The Institute of Chartered Accountants in Australia.

Hazari, S., North, A., \& Moreland, D. (2009). Investigating pedagogical value of wiki technology. Journal of Information Systems Education, 20(2), 187-198

ICAA, \& CPA (2009). Professional accreditation guidelines for higher education programs. Retrieved from http://www.cpaaustralia.com.au/cps/rde/xbcr/cpasite/Professional_accreditation_guidelines_for_higher_education_programs.pdf

Lending, D. (2010). Using a wiki to collaborate on a study guide. Journal of Information Systems Education, 21(1), 5-14.

Matthew, K. I., Felvegi, E., \& Callaway, R. A. (2009). Wiki as a collaborative learning tool in a language arts methods class. Journal of Research on Technology in Education, 42(1), 51-76.

Matthews, R., Jackson, M., \& Brown, P. (1990). Accounting for higher education: Report of the review of the accounting discipline in higher education. Canberra, Australia: Australian Government.

McCarthy, J. (2009). Utilising Facebook: Immersing generation-Y students into first year university. Ergo: The Journal of the Education Research Group of Adelaide, 1(2), 39-49.

McInnis, J. R., \& Devlin, M. (2002). Assessing learning in Australian universities: Ideas strategies and resources for quality in student assessment. Melbourne: Centre for the Study of Higher Education and Canberra (AUTC).

Mears, D. (2009). Podcasts and wikis: Delivering content information to students using technology. Strategies: a journal for physical and sport educators, September/October, 29-34.

MIT OpenCourseWare. (2012). Our history. Retrieved from http://ocw.mit.edu/about/our-history

Pfaff, E., \& Huddleston, P. (2003). Does it matter if I hate teamwork? What impacts student attitudes towards teamwork? Journal of Marketing Education, 25(1), 37-45.

Ruyters, D., Douglas, K., \& Law, F. (2011). Blended learning using role-plays, wikis and blogs. Journal of Learning Design. 4(4), 45-55. Retrieved from https://www.jld.edu.au/article/view/88/88

Sheahan, P. (2005). Generation Y: Thriving and surviving with Generation Y at work. Prahran, Australia: Hardie Grant. 
Underwood, J. D. M. (2003). Student attitudes towards socially acceptable and unacceptable group working practices. British Journal of Psychology, 94(3), 319-337.

Warner, R. (2009). Doing it the Wimba way - an initial evaluation of a voice tool for learning.

Ergo: The Journal of the Education Research Group of Adelaide, 1(2), 59-72.

WikiEducator, (2012). Welcome to WikiEducator. Retrieved from http://wikieducator.org

Wikipedia. (2012). Wikipedia. Retrieved from http://en.wikipedia.org

Wiley, D., \& Gurrell, S. (2009). A decade of development. Open Learning: The Journal of Open Distance and e-Learning, 24(1), 11-21.

Copyright $\odot 2012$ Robyn Davidson 